z told Willerslev and Anzick that they should rebury the child where he was found. "I think you need to put the little boy back where his parents left him," Doyle recalls telling them.

Doyle and Willerslev then set off on a 1,500-kilometre road trip to meet representatives of four Montana tribes; Doyle later consulted another five. Many of the people they talked to had few problems with the research, Doyle says, but some would have preferred to have been consulted before the study started, and not years after.

Willerslev says that researchers studying early American remains should assume that they are related to contemporary groups, and involve them as early as possible. But it is not always clear whom to contact, he adds, particularly when remains are related to groups spread across the Americas. "We have to engage with Native Americans, but how you deal with that question in practice is not an easy thing," he says.

Hank Greeley, a legal scholar at Stanford University in California who is interested in the legal and ethical issues of human genetics, commends the approach of Willerslev's team. But he says that there is no single solution to involving



Native American communities in such research. "You're looking to try to talk to the people who might be most invested in, or connected with, particular sets of remains," he advises.

Dennis O'Rourke, a geneticist at the University of Utah in Salt Lake City, who studies ancient DNA from populations native to the islands around Alaska, notes that indigenous groups have varying concerns: some want remains reburied, others do not, for instance.

The Montana tribes overwhelmingly wanted the Clovis boy's bones interred. Plans for a reburial ceremony, possibly at an undisclosed site, are now being hashed out, with the Crow Nation playing a lead role. It is expected to take place in the spring, after the ground thaws.

\title{
NIH makes wary return to India
}

\section{Some clinical trials funded by US agency resume, but strict regulations have put off others.}

\section{BY SARA REARDON}

\section{A} llayed by pledges that India's strict new rules for clinical trials will be eased, a few principal investigators funded by the US National Institutes of Health (NIH) are cautiously restarting studies there. Clarifications on the rules by the Drug Controller General of India (DCGI), and a promise to soften others, have allowed a small number of researchers to return to their work.

But for most others, the damage has already been done. Trial operators - both academic and industrial - have left India for other countries. Some researchers say that India's clinical trials industry, which boomed over the past decade, may now be grinding to a halt.

"I don't think we're going to walk away from research in India, but it will certainly slow us down," says Daniel Kuritzkes, a virologist at Harvard University in Cambridge, Massachusetts, and head of the international AIDS Clinical Trials Group (ACTG). Last March, after the new rules were announced, his group suspended two NIH-funded antiretroviral drug trials and a cervical cancer screening trial. The latter has resumed patient enrolment now that the DCGI has clarified that the rules apply only to drug trials. But the antiretroviral trials were completed elsewhere, and the group has been unable to enrol Indian patients in new trials for tuberculosis and HIV drugs. "Obviously we have to continue research with or without our Indian colleagues," Kuritzkes says. "We would much rather do it with them."

Researchers had flocked to India because trials are cheap to conduct and there are many

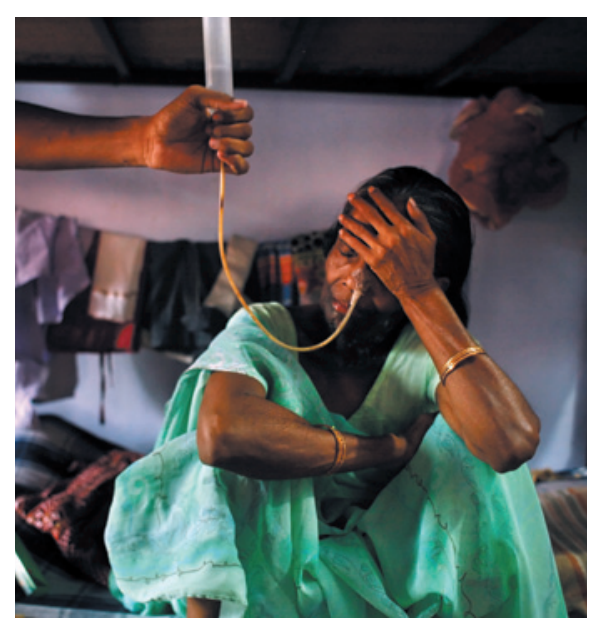

A woman is treated in a Mumbai cancer trial. people with disease who can be signed up. But a crackdown began in January last year, when India's Supreme Court, concerned about allegations of unethical practices and deaths linked to trials (see go.nature.com/aa5xl2), imposed a ban on new ones. It told the DCGI to tighten its regulations, and the agency responded with a set of tough new rules to beef up patient protection.

In response, the NIH placed at least 35 ongoing clinical trials on hold. The law was vague and open to interpretation, researchers say: it seemed that trial sponsors would be required to provide medical care for trial participants for the rest of their lives, regardless of whether the trial itself had caused a medical problem. It also seemed that patients who received placebos, or for whom the drug did not work, would be entitled to compensation. "They went from one extreme to the other extreme," says Kiran Mazumdar-Shaw, chief executive of Biocon, which is based in Bangalore and is one of India's largest biotechnology companies.

Mazumdar-Shaw says that Biocon has already moved some of its trials to other countries, including ones that are far more expensive to operate in than India. She is particularly concerned about a requirement imposed by the Supreme Court in October to make a 
videotape of each trial participant giving informed consent - for a vaccine trial, that could mean videotaping thousands of patients. Meanwhile, several other companies have closed their Indian branches. In October the clinical trials contractor Quintiles, based in Durham, North Carolina, closed its phase I unit in Hyderabad, and on 31 January AstraZeneca, headquartered in London, announced plans to shut its Bangalore centre, although

"The whole

thing has had a very chilling effect for clinical trials and foreign sponsors." both companies maintain other facilities in India and say that the closures are due to restructuring. "The whole thing has had a very chilling effect for clinical trials and foreign sponsors," says Amita Gupta, a researcher on ACTG trials at Johns Hopkins University in Baltimore, Maryland. "The motivation is coming from the right place, but the government overstepped."

The health ministry that oversees the DCGI recognized this overstep and asked for recommended changes from a six-member panel led by Ranjit Roy Chaudhury, a pharmacologist and a former board member of the Medical Council of India. The panel's July report gave various fixes, among which was a recommendation to scrap compensation for participants who received a placebo.

They also specified a new formula to calculate how much a participant who was harmed by a trial should be paid and suggested the formation of a national board to approve institutions' ethics committees, which are responsible for determining whether an injury resulted from a trial and making sure informed consent was properly given. "We don't want a single case of unethical practice", says Y. K. Gupta, a pharmacologist at the All India Institute of Medical Sciences in New Delhi, who is helping to put together the board.

The DCGI has promised to implement most of the panel's suggestions and has presented them to Parliament, which would need to codify the reforms. Already, some changes seem to be occurring; on 24 January, the agency announced that it would approve new clinical trials within six months of their submission. In addition, it clarified that an indemnity insurance requirement - insurance that would have been illegal for the NIH to buy under US law - can instead be purchased by partner institutions within India. Now that the rules are being clarified, Chaudhury hopes that researchers will reconsider their decision to suspend trials.

Yet, until researchers see laws in place, many will remain wary, says Amita Gupta. "I think a lot of groups don't want to deal with the headache." -
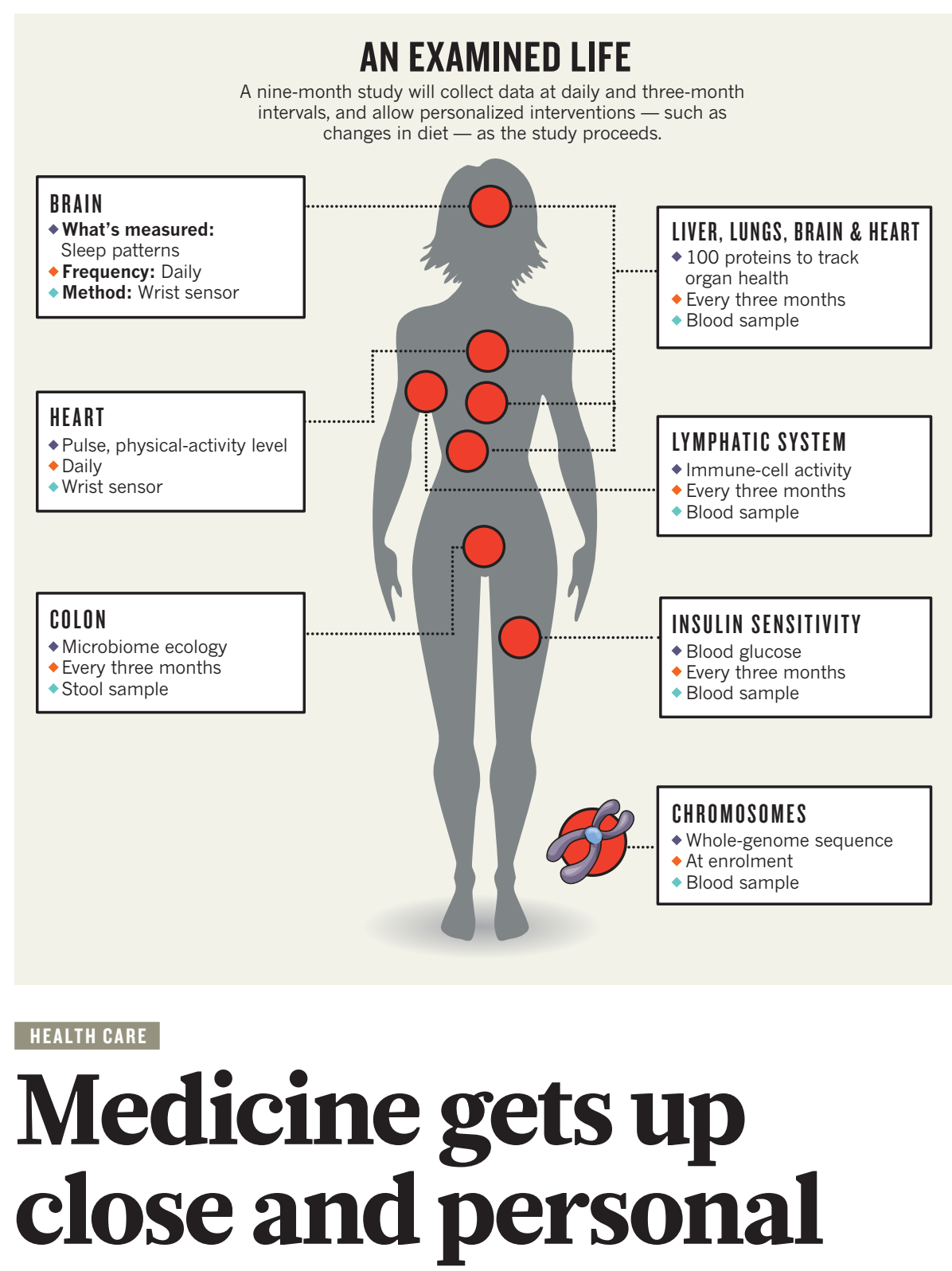

\section{Long-term study will monitor healthy people in detail - and encourage them to respond to the results.}

\section{BY W. WAYT GIBBS}

$\mathrm{L}$ eroy Hood, president of the Institute for Systems Biology (ISB) in Seattle, Washington, likes to talk about what he calls $\mathrm{P} 4$ medicine: health care that is predictive, preventive, personalized and participatory. Medicine today is a string of infrequent interventions prompted mainly by symptoms of illness. Hood argues instead for continuous management of health, making full use of whole-genome sequencing and biomarkers to correct disease before it gains a foothold.

In March, Hood will embark on the first big test of his ideas: a nine-month pilot study, dubbed the Hundred Person Wellness Project, in which 100 healthy individuals will be intensively monitored (see 'An examined life'), offered regular feedback and counselled on lifestyle changes such as shifts in their dietary or sleep habits. The effects of these behavioural changes on their health will, in turn, be tracked using a battery of diagnostic tests.

The study violates many rules of trial design: it dispenses with blinding and randomization, and will not even have a control group. But Hood is confident in its power to disrupt the conventional practice of medicine. "We hope to develop a whole series of stories about how actionable opportunities have changed the wellness of individuals, or have made them aware of how they can avoid disease," he says.

If the pilot study works as hoped, it will 